Bodil Kleve, førsteamanuensis

Fakultet for lcererutdanning og internasjonale studier

Høgskolen i Oslo og Akershus

Sylvi Penne, professor

Fakultet for lcererutdanning og internasjonale studier

VISIONS

Conference

2011:

Teaching

Høgskolen i Oslo og Akershus

\title{
Norsk og matematikk i et literacy-perspektiv: metabevissthet også for de svake elevene
}

\section{Sammendrag}

Artikkelen er diskuterende med fokus på teoretiske perspektiver som i didaktisk sammenheng kan brukes til å synliggjøre likheter og ulikheter mellom skolefag. Vi fokuserer spesielt på svake elever som trenger aktive og språkbevisste lierere. $V i$ tar utgangspunkt i et bevisstgjørende didaktisk metaperspektiv (literacyperspektiv) og et fenomenologisk meningsperspektiv og argumenterer på tre ulike nivå som alle fremmer metaspråklig perspektiv og innsikt. Det første er diskursnivået. Det neste er sjangernivået. Diskursnivået og sjangernivået er nødvendige metaperspektiv i all skolefaglig lcring. Til slutt en erkjennelse av lareprosessens grunnleggende perspektiv: De ulike tenkemåter, "modes of thought", som er nødvendig for laring i de to fagene. Bevissthet om de to tenkemåtene, "modes of thought", tydeliggjør likheter og forskjeller mellom norsk og matematikk.

\section{Bakgrunn}

Til tross for demokratisering, reformering og økende investering i norsk skole og utdanning øker de sosiale ulikhetene i den norske skolen og i det norske utdanningssystemet, slik de øker i andre land (Bakken, 2004; Bordieu, 1995; Zevenbergen, 2001). Det er mange og kompliserte sosiokulturelle årsaker til at dette skjer, men noen kan knyttes direkte til språk, sjangrer og diskurser i en skolekontekst (Bruner, 1996a; Gee, 2003; Penne, 2006). Det er dette som er tema for denne artikkelen. Vi argumenterer for at høyere metabevissthet om språk og tenkemåter vil øke alle elevers muligheter for læring. I en didaktisk sammenheng som her, fokuserer vi mest på de elevene som i skolediskursen karakteriseres som svake. Med utgangspunkt i fagene norsk og matematikk vil vi vise hvordan tverrfaglige perspektiver i to så ulike fag kan, nettopp i kraft av sin ulikhet, virke metaspråklig bevisstgjørende. Vi baserer argumentasjonen på Bruner (1986) og på teoretikere som har videreutviklet hans læringsteorier. Et 
hovedtema for Bruner er nettopp at vi lærer gjennom språk, og at vi lærer ved å være bevisst læringssituasjonen, ved å være metabevisst (Bruner, 1996a).

Denne metaforståelsen vil vi i det følgende kalle literacy, i tråd med didaktikkens nye definisjoner av begrepet (Gee, 2003; Olson, 1994, 2003). Literacy-kompetanse utvikles først og fremst gjennom omgang med og bevissthet om ulike typer skriftlige kilder. Ulike skolefag medieres gjennom ulike diskurser og ulike tekster og teksttyper. Å mestre et skolefag er å bli bevisst, det vil si metabevisst, essensielle diskursive likheter og ulikheter mellom dette faget og andre fag:

To be literate it is not enough to know the words; one must learn how to participate in the discourse of some textual community. And that implies knowing which texts are important, how they are to be read and interpreted, and how they are to be applied in talk and action.

(Olson, 1994, s.273)

Gee (2003) understreker forskjellen mellom "acquisition" og "learning," tilegning og læring, og minner om at det mange elever allerede langt på vei har tilegnet seg når de begynner på skolen, må de andre aktivt lære. Det er et problem som reformpedagogikk og elevaktivisering har hatt en tendens til å overse. Undervisning som hovedsakelig er basert på tilegning gjennom elevaktive handlinger og ikke på metaspråklig bevisstgjøring, vil kunne forsterke de forskjellene som allerede fins.

Metaspråklig bevisstgjøring og literacy-kompetanse kjennetegner «vinnerne» i den norske skolen (Bakken 2004, Penne 2006) som det gjør i andre land. Bruner (1996a) gjør dette til sitt hovedpoeng når han diskuterer sosiale ulikheter i skolen:

If the limits imposed by the languages we use are expanded by increasing our "linguistic awareness," then another function of pedagogy is to cultivate such awareness. [...] In sum then, "thinking about thinking" has to be a principal ingredient of any empowering practice of education.

(Bruner, 1996a, s. 19)

I det følgende diskuterer vi ulikheter og likheter mellom de to skolefagene norsk og matematikk. Norskfaget omhandler blant annet elevenes tale- og tenkespråk. For svake elever er det vanskelig å skille hverdagsspråk og skolefagspråk i norskfaget (Penne 2006). Matematikk kan for de samme elevene utgjøre kompliserte møter med det fremmede (Zevenberger 2001). De får med andre ord problemer i begge fag. Vårt hovedpoeng her er derfor å diskutere elevers læringsmuligheter i et literacy perspektiv.

Vi argumenterer på tre nivå. Først diskuteres norsk og matematikk på diskursnivå, deretter på sjangernivå. Til slutt tar vi et fenomenologisk perspektiv og undersøker fagene med utgangspunkt i Bruner's (1986) "modes of thought" 
eller tenkemåter. Hvordan foregår tenkning og meningsskaping i de to fagene og hvilke didaktiske konsekvenser kan vi trekke av det? Hovedtyngden i vår diskusjon er på det siste nivået, dvs. på nivået som omhandler Bruners to tenkemåter. For ytterligere å understreke viktigheten av dette nivået, belyser vi den teoretiske diskusjonen med empiri fra klasserommet og eksempel fra lærebøker.

\section{Literacy og primære og sekundære diskurser}

Bakgrunnen for et literacy-perspektiv på læring er å få innsikt i sammenhengen mellom språkproblemer og skoleproblemer. Vi har til nå klargjort hvordan vi skal presentere ulike nivå som elevene må bli bevisst gjennom en læringsprosess. I dette avsnittet vil vi beskrive de hverdagsdiskursene som elevene på ulike måter møter skolen og fagene med. Det er i møtet mellom disse to diskursive nivåene at problemene oppstår, eller motsatt, at eleven føler seg hjemme i skolekonteksten og umiddelbart skjønner hva faget dreier seg om.

Elevene kommer til skolen med ulik forforståelse i forhold til skolens handlinger og mål, ulike vaner, ulike erfaringer med bøker, med lesing, med regning, ulik affinitet til bokstaver og tall. Denne totale forforståelsen, som består av erfaringer, språk, vaner, følelser kaller James Paul Gee for elevenes "primærdiskurs" (Gee, 2003).

Primary Discourses constitute our first social identity, and something of a base within which we acquire or resist later Discourses. They form our initial taken-for-granted understandings of who we are and who people "like us" are, as well as what sorts of things we ("people like us") do, value, and believe when we are not in public.

(Gee, 2003, s.137)

Sitatet understreker et poeng som underkommuniseres i læreplaner og i pedagogiske tekster, og det er "value," verdier. Primærdiskursen er en verdidiskurs. Den inngår i ulike nettverk av mening. Slik er jeg/vi. Primærdiskursen motiverer, eller motiverer ikke, for skolens mangfoldige handlinger og mål. Noen elever føler seg fort hjemme på skolen i kraft av sin primærdiskurs, andre føler fremmedhet i større eller mindre grad. Det er et problem i en læringskontekst. Skolen handler, ideelt sett, om møter med det fremmede, med annerledes tenkning og tekster. Dette kaller Gee "sekundærdiskurser." Det er åpenhet for og ny forståelse av sekundærdiskurser som er skolens viktigste oppgave.

Vi har tidligere pekt på Gees markering av forskjellen mellom "acquisition" og "learning," tilegning og læring. Det mange elever allerede langt på vei har "tilegnet seg” i hjem og nærmiljø, må andre aktivt lære på skolen. Denne erkjennelsen må ifølge Gee få konsekvenser for undervisningen:

Teaching that leads to learning uses explanation and analyses that break down material into its analytic bits and juxtaposes diverse Discourses and their practices to each 
other. Such teaching develops meta-knowledge. While many "liberal” approaches to education look down on this mode of teaching, I do not; I have already said that I believe that meta-knowledge can be a form of power and liberation.

(Gee, 2003, s.145)

Ifølge Gee innebærer literacy for elevene å beherske ulike former for "uses of language in secondary discourses”. Forutsetningen er metaspråklig avstand i læringsprosessen, kontekstforståelse, tolkning og handling. På samme vis defineres literacy av Unesco:

Literacy is the ability to identify, understand, interpret, create, communicate, compute and use printed and written materials associated with varying contexts. Literacy involves a continuum of learning to enable an individual to achieve his or her goals, to develop his or her knowledge and potential, and to participate fully in the wider society.

(Unesco, 2004)

Zevenberger (2001) retter fokus mot potensielle vanskeligheter mange elever vil møte i skolematematikken. Hun understreker, som Gee, at elever med ulik sosial bakgrunn kommer til skolen, og til matematikkundervisningen, med ulike erfaringer med matematisk tenkning og, ikke minst, med ulike språklige erfaringer. Noen elever, vanligvis fra middelklassen, er dermed disponert ("predisposed") til å lære matematikk, ikke på grunn av medfødte evner, men som en følge av språklig erfaringsbakgrunn. Disse elevene er bedre i stand til å finne seg til rette i den matematikk-kulturen som oppstår i klasserommet og dermed til å posisjonere seg fordelaktig i forhold til læreren. For andre elever vil det motsatte skje.

Den bakgrunnen som her er skissert, oppstår også i norske klasserom. Penne (2006) viser på samme måte hvordan ulike vaner, verdisystem, språklige erfaringer og forforståelse fører til ulike resultat i norsktimene på ungdomstrinnet.

\section{Diskurser, sjangrer og tenkemåter - tre ulike metanivå i læringsprosessen}

Det tverrfaglige perspektivet på fagene norsk og matematikk som her følger, skal innledes med Tahtas refleksjoner over forskjellen mellom matematikk og litteratur - en sentral del av morsmålsfaget. "There is a vague, often impenetrable, no-man's-land between the discourse of poets, philosophers or people in general, and the discourse of mathematicians" (Tahta i Pimm, 1987 s. 75).

For å undersøke dette ingenmannslandet diskuterer vi de to fagene på tre ulike metanivå. De to første er diskursnivået, som primært omfatter kulturelle 
relasjoner og meningsnettverk i og utenfor skolen, og sjangernivået, som omhandler gjenkjennelige teksttyper i kulturen som kan gi fellesforståelse og mening. Disse to nivåene handler om metaspråklig bevissthet og gjelder generelt for alle skolefag. Vårt siste nivå, som er et mer fenomenologisk nivå, bevisstgjør spesielt forskjeller og likheter mellom våre to fag, norsk og matematikk. Dette nivået er de to tenkemåter, paradigmatisk og syntagmatisk tenkning (Bruner, 1986). Begge tenkemåtene er nødvendig for læring i norsk og matematikk, både for svake og sterke elever. David R. Olson (2003), som bygger på Bruner, kaller det "modes of apprehension" eller "måter å forstå på" i en skolekontekst: "the frames of reference in terms of which children and adults formulate their experience, the major modes in which they define the discourses or disciplines that are the concern of schooling" (Olson, 2003, s.156). Slik lærer en gradvis å resonnere eller tenke som matematiker eller litteraturviter. På grunn av dette nivåets sentrale posisjon i vår argumentasjon, underbygges dette med data fra egen forskning.

\section{Diskursnivået}

En diskurs er en form for meningsfellesskap - felles måter å tenke på i ulike kulturelle kontekster. Diskurser kan gi mening, følelse av inkludering og identitet, for eksempel i skolesammenheng. Innenfor en diskurs kan noe være ganske selvsagt, mens andre aspekter er mer åpne og i bevegelse. Slik formulert av Gee (2001):

We can think of Discourses as identity kits. It's almost as if you get a tool kit full of specific devices (i.e. ways with words, deeds, thoughts, values, actions, interactions, objects, tools, and technologies) in terms of which you can enact specific activities associated with that identity.

(Gee, 2001, s. 720)

Potter og Wetherell (1987) snakker om et diskursivt "interpretative repertoire" som blir meningsskapende medium i hverdagsforståelsen. Et nøkkelord vil alltid være gjenkjennelse på ulike diskursive nivå. Lærerne som underviser i norsk og matematikk, representerer ulike faglige diskurser. Det samme gjør lærebøkene i de to fagene. Faglærerne befinner seg innenfor en diskurs som utgjør deres "selvsagte" verden med ulike "identity kits". Det er mer usikkert med deres elever. Noen kommer fra hjem som har gitt en viss forforståelse for møter med ulike fag, møter med fremmedhet, det vil si sekundærdiskurser (Gee, 2003). Andre finner liten gjenkjennelse uten lærerens hjelp. Solomon (2009) framhever hvordan denne fremmedheten i møte med fagets diskurser, som de svakeste ofte har, bare kan avhjelpes av en lærer som lærer elevene matematikk som sekundærdiskurs.

Dowling (2001) gir et eksempel på diskursive problemer som kan skape problemer i matematikktimene. Han skiller mellom to tilnærminger til tolkning av matematikken, nemlig et praktisk domene og et esoterisk domene. Reglene, 
språket og prinsippene elevene trenger å kjenne igjen og følge for å beherske skolematematikken, gjør at de må kunne jobbe på et avansert diskursivt nivå hvor sammenhenger mellom matematiske objekter befinner seg. Da befinner man seg innenfor det esoteriske domene. I tillegg vektlegger skolematematikken også praktisk anvendelse, og for de svake elevene knyttes ofte matematikken til dagliglivet. Dowling snakker om "low discursive saturation". Da faller elevene ut av matematikk-diskursen, og med Gee kan vi si at de er tilbake i sin primærdiskurs der man ikke er særlig metabevisst. En kan heller snakke om tilegning og ikke om læring (Gee 2003).

Walkerdine (1988) peker på det samme. Å bruke tall i en shoppingkontekst er et vanlig tiltak for å forenkle matematikken for de som ikke forstår diskursen, men det er ikke det samme som å studere tallforhold og tallmønstre i matematikk slik det gjøres innenfor matematikkdiskursen. Slik vil svake elever risikere å bli holdt utenfor det diskursive fellesskap som matematikk skal være for elevene. De som mangler forforståelse, risikerer å bli fortsatt utestengt selv om hensikten er det motsatte.

Kleve (2007) presenterer tilsvarende data fra norske skoler på ungdomstrinnet. De svakeste elevene ble undervist annerledes enn de som var flinkere mer mekanisk læring og fokus på faste metoder og prosedyrer. Videre ble de svakere sjelden utfordret til å se sammenhenger mellom ulike matematiske områder. Penne (2006) presenterer lignende data fra norsktimene. Lærerne var mer interessert $\mathrm{i}$ at elevene gjorde og fullførte oppgavene enn i hvordan de faktisk forsto og tolket det de leste, eller mer generelt hvordan de forsto og brukte læreboken. Deres eventuelle fremmedhet ble sjelden tematisert i timene eller i tilbakemeldinger. Igjen faller de svake ut av det diskursive meningsfelleskapet som faget kan være.

\section{Sjangernivået, den avgjørende forforståelsen}

Det neste nivået som må avklares i didaktisk sammenheng, er sjangernivået. Ifølge Maagerø og Skjelbred (2010) er sjanger "en tekstart som er styrt av visse konvensjoner som over tid manifesterer seg som teksttradisjoner" (s. 24). Hyland’s (2003) definisjon er følgende:

Genre refers to abstract, socially recognised ways of using language. It is based on the assumptions that the features of a similar group of texts depend on the social context of their creation and use, and that those features can be described in a way that relates a text to others like it and to the choices and constraints acting on text producers.

(Hyland, 2003, s. 21)

Den eventuelt klare distinksjonen mellom diskurs og sjanger er omdiskutert. Vi kan imidlertid skille mellom språkvitenskapelige tradisjoner som omhandler trykte teksttyper, der gjenkjennelig form inngår, og et utvidet sjangerbegrep som inkluderer handlinger og inngår i et bredt spekter av vitenskapsfag (Ledin, 2001; 
Ongstad, 2005). Vårt anliggende her er trykte teksttyper basert på kulturelle konvensjoner.

Når målet er utvikling av metaspåklig bevissthet og literacy slik som her, er det helt nødvendig å avklare sjangergrenser for elevene, først tydelige distinksjoner, deretter eventuelle blandingsversjoner (Rosenblatt, 1985). En grunn er den stadig økende kompleksiteten i elevenes tekstverden. Et annet aspekt er nye sjangerblandinger i tida, en tendens både i kunsten og i mediekulturen. Et tredje aspekt er at sosiale medier i større grad er basert på deltakernes hverdagsspråk, deres primærdiskurs. Det blir stilt færre krav til sjangerbevissthet, og metabevissthet oppstår i liten grad. Samtidig har skolediskursen blitt mer uformell og avslappet. Skriveopplæring har for eksempel i Norge vært knyttet sterkt til elevenes verden, deres primærdiskurs (Berge, Evensen, Herzberg \& Vagle, 2005). Det samme viser Solomon (2009) fra engelske klasserom. Matematikkdidaktikeren Solomon ønsker seg derfor tydeligere sjangermarkeringer i morsmålsfagets skriveopplæring. Slik kan elevene lære seg å bli bevisst sjangergrenser også i fag som matematikk. Dette er spesielt viktig for de svake elevene.

Feldman og Kalmar (1996) illustrerer hvor viktig det samme er i morsmålsfaget. I en større studie fikk litteraturstuderende og lesevante collegestudenter opplest en litterær tekst. Halvparten får vite at det er en fiksjonstekst, den andre halvparten får beskjed om at den samme teksten er en biografi. Resultatet er totalt ulike "lesninger" av den samme teksten. Nøkkelordet her er "forforståelse." Det som er tydelig, er at forsøkspersonene leter aktivt etter gjenkjennende tegn i teksten som kan bekrefte den sjangerrammen de har fått oppgitt. Forforståelsen av en biografi og en litterær tekst skaper ulik opplevelse, ulike tolkningsrammer og ulik erkjennelse. Forskerne Feldman og Kalmar konkluderer: "The position we take here is that genre patterns are cognitive models that are derived from exposure to texts that embody them but are then imposed on texts by readers who know them as an interpretive lens. They are in the text and in the mind "(kursivert her), (s. 107/108.)

Selv om pensum i ulike fag formidler mange ulike sjangrer, og selv om lærerne selv anvender dem, viser forskning fra klasserommene at sjangergrensene sjelden blir klargjort for de svake elevene som, sagt med Feldman and Kalmar, mangler en gjenkjennende forforståelse. Læreres utfordringer er å være tydelig og bevisst på sjangergrenser i alle fag. Cochran-Smith (1994) viser det samme for engelskfaget (morsmålet). Også hun snakker om forforståelsen som trengs for å gjenkjenne og avkode sjangersignalene som skal til for å kunne tolke teksten relevant i konteksten. Martin, Christie og Rothery (1994) viser flere eksempler på det samme i matematikkfaget. De flinke elevene kommer til timene med den nødvendige forforståelsen. De svake trenger lærerens hjelp for å forstå de underforståtte og usagte sjangerreglene. Ifølge Hyland (2003) er både diskurs og sjangerbevissthet helt uvurderlig i et literacy-perspektiv: 
... the most effective means for learners to both access and critique cultural and linguistic resources ... The provision of a rhetorical understanding of texts and a metalanguage to analyze them allows students to see texts as artifacts that can be explicitly questioned, compared, and deconstructed, so revealing the assumptions and ideologies that underlie them.

(Hyland, 2003, s.125)

\section{Modes of Thought: Bevisstgjøring om tenkemåter i norsk og matematikk}

Vi har til nå pekt på at diskurser skiller våre to fag, diskurser definert som kulturelle meningsfellesskap, meningsfellesskap som alle elever må bli bevisst. Videre har vi pekt på ulike sjangrer i de to fagene, norsk og matematikk. Sjangrene er på den ene siden uttrykk for ulike teksttradisjoner og på den andre siden del av elevens forforståelse, kognitive rammer for forståelse som er nødvendig for faglig videreutvikling (Bruner, 1986; Cochran-Smith, 1994; Feldman \& Kalmar, 1996).

Det siste punktet i denne artikkelen skal handle om bevisstgjøring om måter å tenke på, "modes of thought." Vi vil peke på hvordan denne bevisstgjøringen kan gi en tverrfaglig og flerfaglig effekt. Fagene norsk og matematikk tilhører to ulike vitenskapsfelt med ulike typer hypoteser, ulike typer argumenter fram mot ulike typer konklusjoner. Dette krever følgelig forskjellige tenkemåter. Det er nødvendig, men ikke nok, å arbeide med bevisstgjøringen på diskurs- og sjangernivå.

Bruners (1986) artikkel "Two Modes of Thought" gir en beskrivelse av de to tenkemåtene. Han skiller mellom det han kaller paradigmatisk og syntagmatisk tenkemåte. Paradigmatisk tenkemåte er knyttet til vitenskapelig tenkemåte som krever argumenter basert på dekontekstualiserte generaliseringer og forklaringer (som matematikk). Tenkemåten forutsetter erkjennelsen av et abstrakt system som "eksisterer evig" som sann uforanderlighet. Den andre tenkemåten er motsatt. Den krever rett og slett en kontekst som bakgrunn for forståelsen. Denne konteksten skal tolkes hermeneutisk der deler tolkes i lys av helheter og omvendt (som norskfaget). Bruner (1986) skriver:

Let me begin by setting out my argument as baldly as possible, better to examine its basis and its consequences. It is this. There are two modes of cognitive functioning, two modes of thought, each providing distinct ways of ordering experience, of constructing reality. The two (though complementary) are irreducible to one another. Efforts to reduce one mode to the other or to ignore one at the expence of the other inevitably fail to capture the rich diversity of thought.

Syntagmatisk tenkning, norskfagets tenkning, som også er nært beslektet både med primærdiskursen og med hermeneutikken i litteraturens verden, får mest plass i Bruners framstilling fordi han mener den har fått for lite oppmerksomhet i didaktisk sammenheng, og fordi dens nærhet til hverdagstenkningen gjør at det er ekstra viktig å få et metabevisst forhold til den. Syntagmatisk tenkning er 
primært narrativ og har følgelig et subjektivt utgangspunkt og kan derfor aldri formidle noen definitiv "sannhet" om det vi ser og opplever. Det er en "opplevd" verden - ingen "sann" verden. Vi må derfor tolke dens hendelser og handlinger innenfor kontekster som kan forklare deler i lys av helheter og omvendt. Bruners todeling gir også nye og vektige argumenter for god litteraturundervisning som bevisstgjøring av syntagmatisk tenkning. Når vi kommuniserer og tenker syntagmatisk, er den narrative strukturen vårt mest gjennomgripende kognitive skjema (Bruner, 1986, 1990, 1996a; Lakoff \& Johnson, 1999; Vygotsky, 2001).

Syntagmatisk tenkning er derfor alltid knyttet til konkrete kontekster som skal tolkes. Den andre tenkemåten, paradigmatisk tenkning, er annerledes. Da slutter vi å tolke, men leter i stedet etter forklaringer og søker dekontekstualiserte generaliseringer. Det er slik vi skaper mening, det er slik vi lærer - i hverdagen, i vitenskapen, i norsk eller matematikk. Samtidig er det, som Bruner poengterer, like viktig å fastholde at det er urealistisk å tro at de kan skilles ad at vi kan velge den ene og stenge den andre ute. Slik fungerer vi ikke. Vi trenger stadig den ene for å forstå den andre. Den ene tenkemåten utelukker ikke den andre i noen av fagene eller for noen elevgrupper, men de inngår i system som elevene skal bli bevisst. Det kreves metabevissthet.

Oatley (1996) viser til Bruners "Two modes of thought" og hevder at objekter uttrykt i den narrative (syntagmatiske) tenkemåten er lettere å forstå, mens objekter uttrykt i den paradigmatiske tenkemåten møter mer motstand. Han viser hvordan Newtons tredje lov kan forklares enten narrativt eller ved hjelp av en matematisk ligning (paradigmatisk tenkemåte). Han understreker dermed nødvendigheten av begge tenkemåtene i fysikken, og vi skal også se eksempel på hvordan en matematikklærer gjorde nytte av begge tenkemåtene i en matematikktime.

\section{Tolkning og forklaring: Norsk versus matematikk}

I denne delen går vi mer detaljert inn i fagene norsk og matematikk for å illustrere hvilken betydning bevisstheten om de tre nivåene har. Som tidligere nevnt, legger vi spesielt vekt på «modes of thought.» I vår diskusjon om temaet «generalisering og argumentasjon» underbygges våre argumenter med empiriske data fra både matematikk og norsk.

De to velkjente illustrasjonstypene (fig.1) som her følger fra en matematikkbok, der elevene skal fargelegge riktig antall, og et utdrag fra en lærebok i norsk for videregående skole, illustrerer visuelt to ulike faglige diskurser. Bananer, hus og båter har i matematikkboka ingen funksjon som bananer, hus og båter. De har ingen kontekst. De "fins" rett og slett ikke. De er umiddelbare uttrykk for det abstrakte system som matematikkfaget handler om. 


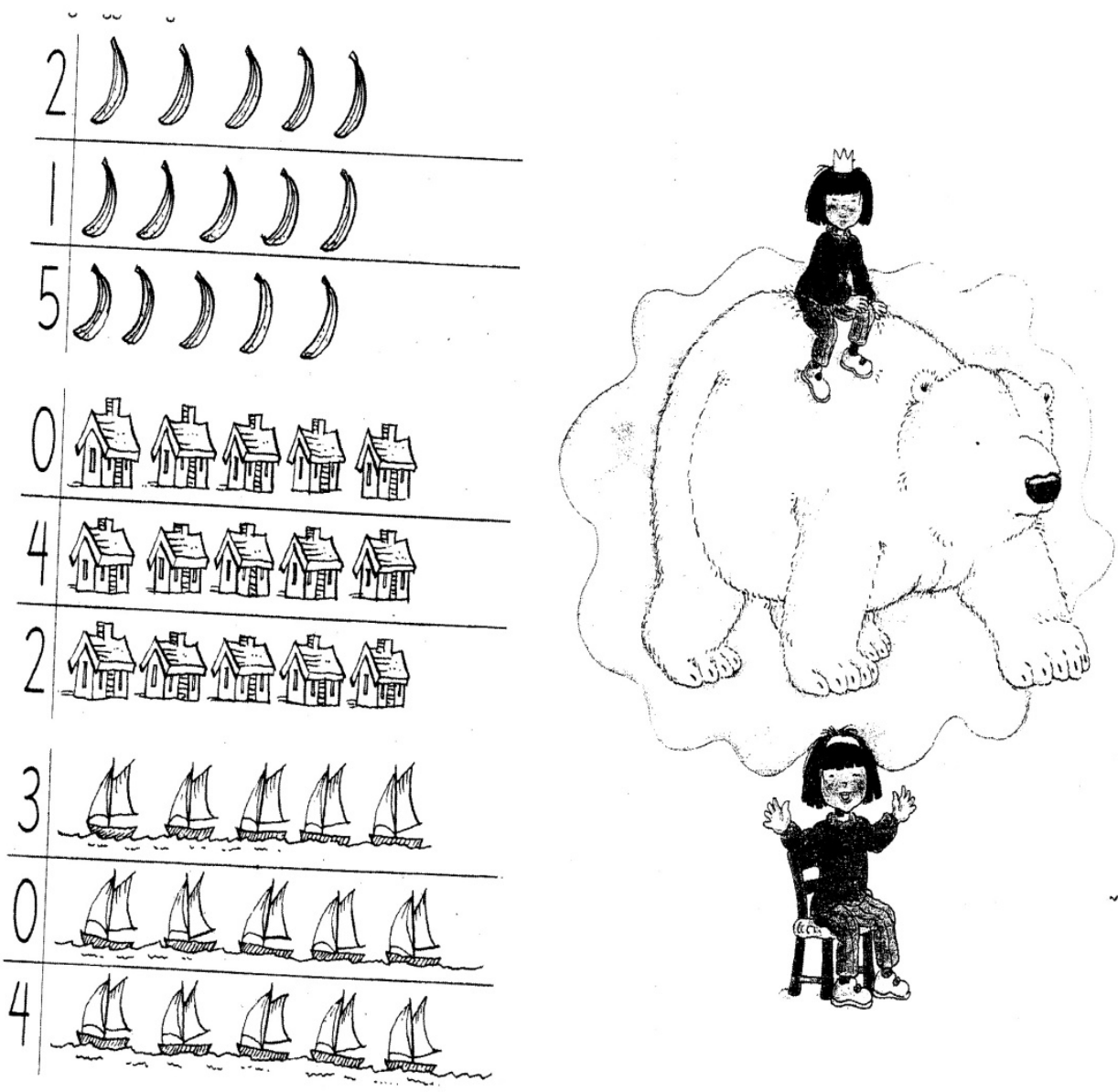

\section{Figur 1}

(Venheim, Olstorpe, \& Skoogh, 1989; Eik, 2003)

Fra et literacy-perspektiv er det viktig å være klar over at når eleven åpner en hvilken som helst norsk- eller matematikkbok for barnetrinnet, forholder hun seg til to ulike fagfelt som kommuniserer gjennom ulike diskurser. Elevene trenger videre å være bevisst hvilke sjangrer de ulike fagene kommuniserer $\mathrm{i}$. Videre er bevissthet om «modes of thought» essensiell (Bruner, 1986, 1990, 1996b; Feldman \& Kalmar, 1996). Elevene må bli klar over at noe av det viktigste i matematikk er å kunne forklare, mens i norsk er det å kunne tolke. Matematikk-diskursen fører dem inn i en verden som er abstrakt, symbolsk, konseptuell, fylt av gitte logiske systemer og regler, og derved fremmed og underlig i forhold til deres vanlige væren i verden. I norsktimene, derimot, møter de en verden som er så hverdagslig lik deres egen, at de trenger skolens hjelp til å skape nødvendig avstand, en metaspråklig bevissthet om den. De skal ikke forklare sin verden som i matematikktimene. De skal tolke og prøve å forstå hendelser og handlinger i lys av stadig mye kontekster. På samme måte som vi ikke skal forklare og begrunne hendelser i litterære tekster. Vi skal tolke og prøve å forstå dem i den litterære konteksten. Det er viktig at disse distinksjoner gjøres eksplisitt for elevene, spesielt de svake. 
Bruner er opptatt av litteraturens betydning for utvikling av syntagmatisk tenkning. Litteratur handler om menneskelige relasjoner og konflikter, den gir mulighet for empati og innlevelse i andre, enten de er beskrevet som samtidige eller fremstår i fiksjoner fra fortid eller framtid. Bruner understreker stadig hvordan litteratur motsetter seg logiske konklusjoner, at dette er selve poenget med god litteratur: "As any writer or playwright will assure you, his task is to imagine, to explore possibility" (Bruner, 1990, s. 59). Han refererer ofte til Henrik Ibsen for å forklare forskjellen på det han kaller "great art" and "great science":

In Ibsen's A Doll's House, for example, there is no way of arriving logically at their "truth conditions." Is Nora a premature feminist, a frustrated narcissist, or a woman paying the high price for respectability? [...] The interpretation we offer, whether historical or literary or judicial, is, as we have already noted, always normative. They cannot be decomposed into a set of atomic propositions that would allow the application of logical operations.

(Bruner, 1990, s. 60)

\section{Generalisering og argumentasjon i matematikkfaget}

I det følgende sitatet stiller matematikkdidaktikeren Reuben Hersch (1997) opp vårt dilemma og understreker lærernes viktige utfordring i begge fagene. Temaet her er bevis:

[W] hat do we mean when we talk about proving? Immediately I observe that "proof" has different meanings in mathematical practice and in philosophical analysis. What's worse, this discrepancy is not acknowledged, especially not in teaching or in textbooks. How can this be? What does it mean? How are the two proofs related, in theory and practice?

(Hersch, 1997, s. 48)

Til tross for, som Mason (2004) peker på, at vi generaliserer og abstraherer hele tiden, så uttrykkes generaliseringer i matematikk med nøyaktige notasjoner som det videre kan trekkes spesielle eller generelle konklusjoner fra: "Mathematics deals with relationships per se, and so context is of the least importance; hence the prevalence of abstractions in mathematics” (Mason, 2004, s. 132). Generalisering i norskfaget er helt annerledes, noe vi viser i neste del.

På samme måte som Oatley viste til de to tenkemåtene i fysikk, vil vi som eksempel på generalisering i matematikk, og for å understreke vår påstand om at både norsk og matematikk trenger bevisst didaktisk anvendelse av begge "modes of thought,» presentere et utdrag fra en matematikktime i 10.klasse. Datautdraget er hentet fra Kleve (2007).

Læreren hadde tegnet en rettvinklet trekant på tavla og satt målene på katetene til 3.6 og 4.8 . 
1Lærer: Håper dere har kalkulator med, for dere trenger den til den oppgaven som dere skal få nå. Hva slags trekant har vi der Mikkel?

2 Mikkel: Rettvinklet trekant

3 Lærer: Rettvinklet trekant. Så vet vi lengden på to av sidene der. Og nå bruker jeg ikke enhet. Nå er vi bare interessert i tallene. Hvordan kan jeg finne den tredje siden, Leif?

4 Leif: $\quad$ Du må bruke Pythagoras

5 Lærer: Yes. Må bruke Pythagoras. Da prøver vi å gjøre det på den trekanten her. Hvis vi da kaller den for $\mathrm{x}$, Leif?

6 Leif: Må ta x i andre lik tre komma seks i andre pluss fire komma åtte i andre (Lærer skrev $\mathrm{x}^{2}=3.6^{2}+4.8^{2}$ på tavla)

7 Lærer: Ja, da regner vi ut det. Tre komma seks i andre er?

8 Elever: Tolv komma nittiseks (Lærer skrev 12.96 på tavla)

9 Lærer: Fire komma åtte i andre er?

10 Elever: Tjuetre komma null fire

11 Lærer: Tjuetre komma null fire (skrev 23.04 på tavla)

12 Elev: Trettiseks

13 Lærer: Det blir trettiseks.

14 Elev: Det blir seks.

15 Lærer: Yes, okay. Den ble 6 lang. Dette her var jo masse regning. Hvis vi ser på de tallene der så kunne vi kanskje gjort det enklere. Er det sånn at, her har jeg lagt til 1.2 [3.6+1.2=4.8] og hvis jeg legger til 1.2 til så får jeg den tredje sida? $[4.8+1.2=6]$ Er det en regel som gjelder alltid? Skal ta et nytt eksempel. Ny trekant (tegner ny rettvinklet trekant hvor katetene er 7.5 og 10). Hvis den er 7.5 og den er 10, blir den da 12.5? Kan dere sjekke om det stemmer?

16 Baard: Ja!

17 Lærer: Det stemte det også. Da er utforskningsoppgaven deres nå: Gjelder det alltid? Gjelder det for hvilken som helst lengde på katetene? Finn på noen nye lengder på katetene og sjekk om det gjelder for hvilke som helst lengder på katetene.

Hvis vi ser på denne episoden fra et literacy-perspektiv, ser vi at frem til utsagn 15 befinner vi oss i den syntagmatiske tenkemåten. Å regne ut en tredje side i en rettvinklet trekant ved å bruke Pythagoras’ læresetning er kjent for elevene. Dette er matematiske handlinger de har gjort mange ganger før. Dessuten loste læreren elevene gjennom utregningene. Men så skjer det et skifte. I utsagn 15 kommer spørsmålet 'Er det en regel som gjelder alltid?' Spørsmålet indikerer en mulig generalisering, et skifte mot paradigmatisk tenkemåte. Men læreren knytter en eventuell generalisering sterkere til det kjente igjen, til den syntagmatiske tenkningen, og tar et nytt eksempel. Regelen gjaldt også her, og læreren beveger seg igjen mot en generalisering: Gjelder det alltid? Gjelder det for en hvilken som helst lengde på katetene? Elevene motiveres igjen til paradigmatisk tenkning.

Senere i samme matematikktime, da elevene hadde funnet ut at det ikke var slik i alle rettvinklete trekanter at man kunne ta differensen mellom katetene og legge til den største kateten for å få hypotenusen, sier læreren: 
Hvis det hadde vært så enkelt som dette i alle tilfeller, så hadde vi vel ikke hatt den regelen her [hun viser til Pythagoras’ læresetning]. Da hadde jeg lurt dere til å regne masse. Neste spørsmål blir da: Hvorfor virker det på disse sidene her? Hva er det som er spesielt med de tallene her? Hvorfor fungerer det på mine eksempler? Se litt på lengden av sidene.

Her ble altså elevene utfordret med et hvorfor. Hvorfor virker det på disse sidene her? Og læreren gir dem et hint og ber dem studere lengden av sidene. Igjen ble de utfordret til å tenke paradigmatisk. En strategi er å finne et mot-eksempel. Det gjorde elevene raskt. Det neste var å finne ut når regelen gjaldt [i.e. når forholdet mellom katetene er 3:4]. Til slutt ble elevene utfordret til å vise at det gjaldt alltid når forholdet mellom katetene var 3:4.

I denne matematikktimen tok læreren med seg elevene mot paradigmatisk tenkemåte som i matematikk blant annet handler om generalisering. For å vise at noe ikke gjelder alltid, er det nok å finne ett mot-eksempel. For å vise at noe gjelder alltid, er det ikke nok med ett, to eller mange eksempler. Men bruk av algebra er en måte å bevise på, generalisere og begrunne når noe gjelder uavhengig av konteksten.

Gjennom utsagnet over: «Gjelder det alltid?» ble elevene utfordret over i en annen tenkemåte. Inntil da hadde de bare utført enkle regneoperasjoner med kalkulator for å finne den tredje siden i trekanten. Eksemplene læreren brukte, spørsmålene hun stilte og sammenhengene hun påpekte, virket medierende for elevenes læring.

\section{Generalisering og argumentasjon i norskfaget}

Som vi har sett, er argumentering i matematikk basert på generalisering, og involverer begrepssystem og årsakssammenhenger. Dette danner grunnlaget for skolefaget matematikk. I tråd med Bruners to tenkemåter, er "generalisering" i norskfaget noe annet. I matematikkfaget er generalisering en forutsetning for matematisk dekontekstualisert argumentasjon. I norskfaget advares sterkt mot generaliseringer når det skal argumenteres. Bakgrunnen er som tidligere referert: norskfaget skal primært tolkes hermeneutisk og kontekstuelt. En hendelse skal forstås i den konteksten den inngår i, på samme vis som argumentasjonen i en rettssal. Det følgende er utdrag fra en lærebok i norsk på videregående skole (Berge, Jomisko, \& Næss, 2006). Her kan vi se at generalisering som argumentasjon vurderes som "lite tillitvekkende," (s.20).

"Generalisering"

En spesiell form for argumentasjon er generalisering. En som generaliserer, trekker allmenne slutninger på grunnlag av enkelttilfeller. I avisene kan vi støte på overskrifter som "uhøflige sjåfører" og "uengasjert ungdom." Det er eksempler på urimelige generaliseringer med utgangspunkt $\mathrm{i}$ enkeltepisoder og enkeltobservasjoner. Generaliseringer blir som regel vurdert som en lite tillitvekkende måte å argumentere på.

(Berge, m. fl., 2006, s. 20) 
Hva er så et godt argument i norskfaget? Et godt argument er basert på refleksjon over personers intensjoner og handlinger innen for handlingskonteksten. Hvilke muligheter har de? Hva er deres intensjon? Hva er et sannsynlig resultat og hvorfor?

Eksempelet viser hvordan elever må forholde seg til begrepet "generalisering" på to ulike måter. I matematikkfaget er generalisering selve målet, i norskfaget er det noe læreboka advarer mot. Dette er en fundamental forskjell som gjør at fagene er det de er. Det krever høy metabevissthet å forklare for seg selv og andre hvorfor det er slik, men når forståelsen er blitt en del av elevenes tenkemåte, både i matematikkfaget og i norskfaget, vil det være en stor ressurs for læring i begge fagene, og for elevenes generelle literacy-kompetanse. Med Gee (2003) vil vi hevde at literacy-kompetanse utvikles best gjennom refleksjon over egen læring og praksis.

\section{Metaforer og norskfaget}

Vi har vist hvordan generalisering skifter fra dekontekstualisert betydning i matematikk til kontekstuell mening i norskfaget. Imidlertid trenger også norskfaget dekontekstualisert generalisering. Litterære tekster, dette gjelder særlig lyrikk, men som vi skal se, også romaner og drama, inneholder generaliserende aspekter som er viktige i forbindelse med tolkning. Dette skjer primært gjennom bruken av metaforer.

For å vise paradigmatisk tenkning knyttet til litteratur kan vi gå til Vygotsky. Når Vygotsky (2001) vil illustrere det siste og mest avanserte stadium av indre tale, er hans eksempel en litterær metafor, nemlig møtet med romanen Døde sjeler (1842) av Nikolai Gogol - først som syntagmatisk utforsking, et møte med en litterær fortelling, og så gradvis over på det vi her har kalt et paradigmatisk nivå. Vygotsky ser møtet med denne metaforiske meningsprosessen som et siste stadium i barnets språkutvikling. Han beskriver Gogols roman som eksempel på denne metaforiske og generaliserende meningsskapingen:

Opprinnelig viste tittelen til døde livegne som ikke hadde fått sine navn fjernet fra de offisielle listene og fortsatt kunne kjøpes og selges som om de var i live. Det er i denne konkrete mening ordene brukes gjennom romanen. Men gjennom sin nære sammenheng med hele verket får disse to ordene gradvis en ny betydning. Når vi kommer til romanens avslutning, betyr "døde sjeler" ikke så mye døde livegne som alle de skikkelsene i fortellingen som lever rent fysisk, men er døde åndelig sett:

(Vygotsky, 2001, s. 212-213).

"Døde sjeler" er altså blitt en generaliserende metafor, et abstrakt begrep for menneskelig dårskap. Litteraturundervisning som for eksempel kvalifiserte møter med Gogols roman eller Ibsens drama, aktiverer begge tenkemåtene. Når handlingen har stilnet, når Hedvig har tatt sitt liv i Vildanden, står metaforene igjen som et "konsentrat av mening," ifølge Vygotsky, og "for å kunne omsette 
det til åpen tale trenger man mange ord.” Elevenes opplevelse, medfølelse og engasjement i Hedvigs tragiske skjebne er hovedsakelig basert på syntagmatisk tenkning. Men "opplevelse" er noe annet enn "erkjennelse." For å kunne dele de erkjennelser som Ibsen eller Gogol formidler, må læreren aktivt føre elevene inn i paradigmatisk tenkemåte der metaforenes universelle utsagn kan gis mening. Eller hva formidler egentlig Jens Bjørneboes roman Haiene om tendenser i samfunnsstrukturer, eller hva formidler Tarjei Vesaas roman Is-slottet om relasjoner mellom mennesker?

\section{Metaforer og matematikkfaget}

Metaforer er også en viktig del av skolematematikken, men der spiller de en annen rolle, ikke den paradigmatiske rollen som i norskfaget. I matematikk brukes for eksempel bananer som antall (figur 1), eller som Bruner (1986) skriver:

Metaphors are crutches to help us get up the abstract mountain, [...] once up, we throw them away (even hide them) in favor of a formal logically consistent theory that (with luck) can be stated in mathematical or near-mathematical terms.

Metaforer brukes ikke for å vise eller bevise noe i matematikk. Mens det i litteraturundervisning kan være nødvendig med metaforer for å understreke selve poenget, brukes metaforer som en lingvistisk teknikk for å hjelpe elevene til å forstå matematikken. Pimm (1987) viser til forekomster av metaforer og den nødvendige rolle de spiller i matematikkundervisningen og oppfordrer lærere til å fortelle elevene om egne metaforer som har virket støttende i deres forståelse av matematikk. Han hevder videre at også elevene bør oppmuntres til å formulere sine egne konseptuelle metaforer, slik at bruken, inkludert begrensningene, av metaforer blir eksplisitt. Dersom metaforen brukes som en konseptuell bro ved innføring av et nytt emne i matematikk, er det også viktig å trekke grensen mellom matematikken og metaforen, som for eksempel i tilfelle av bruk av skålvekt for ligning og maskin for en funksjon. Men Pimm påpeker viktigheten av at det for elevene eksplisitt blir gjort klart at en likning ikke er en skålvekt, ei heller at en funksjon er en maskin. Metaforens begrensninger må avklares slik at selve begrepet og metaforen kan skilles ad.

Bruken av metaforer, nettopp som «krykker» for å lære matematikk, er til stor hjelp, spesielt for de svakeste elevene. Men dersom ikke krykkene blir kastet eller gjemt bort, kan bruken av dem være mer til hinder enn hjelp i læreprosessen. 


\section{Oppsummering og diskusjon}

Sosiale ulikheter er økende i det norske utdanningssystemet (Bakken, 2004). Det er ulike grunner (sosiale, kulturelle) til at elever faller ut av utdanningssystemet. Men som vi har vist i denne artikkelen, fins det en grunn som har med læring å gjøre, og som vi som didaktikere kan gjøre noe med. Vi lærer gjennom språk og ved å bli bevisst, metabevisst, at vi lærer. Et nøkkelbegrep i internasjonal didaktisk sammenheng er derfor literacy-begrepet. Ifølge Gee (2003) innebærer literacy for elevene å beherske ulike former for "uses of language in secondary discourses”. Forutsetningen er metaspråklig avstand i læringsprosessen, kontekstforståelse, tolkning og handling.

Elever som mangler literacy-kompetanse og derved forforståelse i forhold til sekundærdiskurser, møter skolen og skolens tekster med sin primærdiskurs (Bruner 1986; Gee 2003). Vi har argumentert for at disse elevene trenger læreren til å synliggjøre både likheter og forskjeller mellom fag. Internasjonalt er begrepet cross-curricularity sentralt i didaktisk sammenheng. Problemstillingene kretser rundt hva som kan gjøre læringssituasjonen bedre for de svake elevene. Vi har tatt utgangspunkt i den samme tematikken. Med utgangspunkt i literacy-begrepet har vi presentert to ulike fag, det hermeneutiske tolkningsfaget norsk og det generaliserende matematikkfaget, og vi har vist hvor viktig det er, både for elever og for lærere, å bli bevisst likheter og forskjeller i ulike kontekster.

Vi har argumentert på tre ulike teorinivå som alle fremmer metaspråklig perspektiv og innsikt. Det første er diskursnivået der vi også kan vise til egen forskning (Gee, 2001; 2003; Solomon, 2009; Dowling, 2001; Walkerdine, 1988; Kleve, 2007; Penne, 2006). Det neste er sjangernivået (Ledin, 2001; Ongstad, 2005; Rosenblatt, 1985; Feldman \& Kalmar, 1996; Cochran-Smith, 1994; Martin, Christie \& Rothery, 1994).

Det tredje teorinivået underbygger vårt literacy-perspektiv ytterligere. Det tar utgangspunkt $\mathrm{i}$ at bevissthet om to ulike tenkemåter er nødvendig i de to fagene. Norskfaget er primært hermeneutisk og gir mening i en kontekstuell sammenheng. Det som er spesielt med matematikkfaget, er det motsatte. Der skal elevene lære å dekontekstualisere og å generalisere (Bruner, 1986, 1996a). Dette er aspekter som sjelden er framme i didaktiske sammenhenger, spesielt når bakgrunnen er elevorientert undervisning (Olson, 2003).

Bevissthet om ulike tenkemåter er viktige i didaktisk sammenheng, spesielt for de svake elevene som ofte blir møtt med forenklinger. Slik blir fagene enda mer utydelige. «Tilpassingen» til de svake elevenes primærdiskurs (Gee, 2003) kan ha den bivirkning at den stenger dem ute fra fagene (Solomon, 2009). De inkluderes ikke i det diskursive fagfellesskapet som faget utgjør. Sjangrene forblir fremmede, og elevene blir ikke metabevisste nok i fagkontekster til å justere tenkemåter og løsningsmåter. Dette er et literacy-problem som kan utvikles gjennom tverrfaglig bevisstgjøring (Cochran-Smith, 1994; Gee, 2003). 
Gjennom utforskning av forskjellene har vi argumentert for bevissthet om syntagmatisk og paradigmatisk tenkning i begge fag. Som vi har vist eksempler på, er det viktig å gjøre bruk av begge tenkemåter i læringsprosessen - for alle elever, og som tidligere referert: «To be literate it is not enough to know the words; one must learn how to participate in the discourse of some textual community» (Olson, 1994, s. 273).

\section{Referanser}

Bakken, A. (2004). Økt sosial ulikhet i skolen? Tidsskrift for ungdomsforskning, 4(1), 83-91.

Berge, K. L., Evensen, L. S., Herzberg, F., \& Vagle, W. (2005). Norske ungdommers skrivekompetanse, bind II: Norskeksamen som tekst. Oslo: Universitetsforlaget.

Berge, A. L., Jomisko, A. L., \& Næss, E. L. (2006). Spenn. Norsk for studieforberedende utdanningsprogram, VG1. Oslo: Cappelen.

Bordieu, P. (1995). Distinksjonen. Oslo: Pax forlag.

Bruner, J. (1986). Actual minds, possible words. Cambridge, London: Harvard University Press.

Bruner, J. (1990). Acts of meaning. Cambridge, Mass: Harvard University Press.

Bruner, J. (1996a). The culture of education. London: Harvard University Press.

Bruner, J. (1996b). Frames for thinking: Ways of making meaning. I D. R. Olson \& N. Torrance (red.), Modes of thought. Explorations in culture and cognition. Cambridge: Cambridge University Press.

Cochran-Smith, M. (1994). The making of a reader. New Jersey: Ablex Publishing.

Dowling, P. (2001). Reading mathematics texts. I P. Gates (red.), Issues in mathematics teaching (s. 180-196). London: RoutledgeFalmer.

Eik, L. T. (2003). Lekende læring og lærende lek på småskoletrinnet. Oslo: Pelex. Norsk Skoleinformasjon.

Feldman, C. F., \& Kalmar, D. A. (1996). Autobiography and fiction as modes of thought. I D. R. Olson \& N. Torrance (red.), Modes of thought, explorations in culture and cognition. Cambridge: Cambridge University Press.

Gee, J. P. (2003). Social linguistics and literacies. ideology in discourse. New York: Routledge Falmer.

Hersh, R. (1997). What is mathematics, really? New York: Oxford University Press.

Hyland, K. (2003). Genre-based pedagogies: A social response to process. Journal of Second Language Writing, 12(1), 17-29.

Kleve, B. (2007). Mathematics teachers' interpretation of the curriculum reform, L97, in Norway. (Ph. D.-avhandling), Høgskolen i Agder, nr 5, Kristiansand.

Lakoff, M., \& Johnson, G. (1999). Philosophy in the flesh. The embodied mind and its challenge to western thought. New York: Basic Books.

Ledin, P. (2001). Temaintervju "Reflexioner kring genre av fyra nordiska forskare". Rhetorica Scandinavica, 18 (Juni 2001), 2-8.

Maagerø, E., \& Skjeldbred, D. (2010). De mangfoldige realfagstekstene. Om lesing og skriving i matematikk og naturfag. Bergen: Fagbokforlaget.

Martin, J. R., Christie, F., \& Rothery, J. (1994). Social processes in education: A reply to Sawyer and Watson (and others). I B. Stierer \& J. Maybin (red.), Language, literacy and learing in educational practice. Clevedon: The Open University.

Mason, J., \& Johnston-Wilder, S. (2004). Fundamental constructs in mathematics education. London: RoutledgeFalmer. 
Oatley, K. (1996). Inference in narrative and science. I D. R. Olson \& N. Torrance (red.), Modes of thought. Explorations in culture and science (s. 123-142). Cambridge: Cambridge University Press.

Olson, D. R. (1994). The world on paper. The conceptual and cognitive implications of reading and writing. Cambridge: Cambridge University Press.

Olson, D. R. (2003). Psychological theory and educational reform. Cambridge: Cambridge University Press.

Ongstad, S. (2005). Genre. I P. Strazny (red.), Encyclopedia of linguistic. New York: Taylor and Francis.

Penne, S. (2006). Profesjonsfaget norsk i endringstid. Å konstruere mening, selvforståelse og identitet gjennom språk og tekster. Dr. polit avhandling, UV-fakultetet, Universitetet i Oslo, nr 63.

Pimm, D. (1987). Speaking mathematically: communication in mathematics classrooms. London: Routledge \& Kegan Paul.

Potter, J., \& Wetherell, M. (1987). Discourse and social psychology: beyond attitudes and behaviour. London: Sage.

Rosenblatt, L. M. (1985). The transactional theory of the literary work: Implications for research. I C. R. Cooper (red.), Researching response to literature and the teaching of literature. Points of departure. New Jersey: Ablex Publishing Corporation.

Solomon, Y. (2009). Mathematical literacy. Developing indentities of inclusion. London and New York: Routledge.

Venheim, R., Olstorpe, K., \& Skoogh, L. (1989). Regnereisen, Grunnbok 1a. Oslo: Aschehoug.

Vygotsky, L. (2001). Tenkning og tale. Oslo: Gyldendal akademiske.

Walkerdine, V. (1988). The mastery of reason, cognitive development and the production of rationality. London: Routledge.

Zevenbergen, R. (2001). Language, social class and underachievement in school mathematics. I P. Gates (red.), Issues in mathematics teaching (s. 38-50). London: RoutledgeFalmer. 